\title{
Analysis on the Mode of Trans-Regional Allocation of Agricultural Machinery
}

\author{
Li Liu, Tong Chen, Shuguo Yang, Xinli Wang* \\ Heilongjiang Bayi Agricultural University, Daqing, China \\ Email: ^ndliuli@163.com
}

How to cite this paper: Liu, L., Chen, T., Yang, S.G. and Wang, X.L. (2020) Analysis on the Mode of Trans-Regional Allocation of Agricultural Machinery. American Journal of Plant Sciences, 11, 1049-1056. https://doi.org/10.4236/ajps.2020.117075

Received: June 8, 2020

Accepted: July 14, 2020

Published: July 17, 2020

Copyright $\odot 2020$ by author(s) and Scientific Research Publishing Inc. This work is licensed under the Creative Commons Attribution International License (CC BY 4.0).

http://creativecommons.org/licenses/by/4.0/

\section{(c) (i) Open Access}

\begin{abstract}
With the continuous progress of agricultural technology, agricultural mechanization presents a good development trend after half a century development. But agricultural machinery equipment and the level of agricultural mechanization are imbalances in different regions; the structure of agricultural machinery equipment is unreasonable; there are great differences in agricultural mechanization level of different operations and different crops and the whole level of agricultural mechanization social service is not high. Through cross regional allocation of existing agricultural machinery to improve the working efficiency of agricultural machinery; we can extend the operation time of the agricultural machinery and improve the operation effect and income of agricultural machinery.
\end{abstract}

\section{Keywords}

Agricultural Machinery, Trans-Regional Work, Agricultural Machinery Allocation

\section{Introduction}

China is a large agricultural country with a large population. It has a wide area from south to North and obvious seasonal differences, which provides unique conditions for the allocation of agricultural machinery. Agricultural machinery cross regional operation refers to a new agricultural machinery service mode of agricultural machinery cross regional operation, which makes full use of the time difference of crop maturity caused by the obvious climate difference between the vast regions of our country and organizes the cross regional mobile operation service of agricultural machinery to solve the imbalance of supply and demand of agricultural machinery resources between regions and the contradiction between small-scale farmers' planting and large-scale production machine 
social service mode.

\section{Brief Introduction to the Development of Agricultural Machinery Trans-Regional Allocation}

In China, the service mode of agricultural machinery cross regional operation sprouted in the middle and late 1980s, which was originally the spontaneous behavior of farmers. Since 1996, the relevant government departments have brought the trans-regional operation of agricultural machinery into the scope of management and service, and the trans-regional operation of agricultural machinery has developed rapidly. Since 2000, project organization and management of agricultural machinery cross regional operation has been on the right track and entered the standardized development stage. It has created the successful experience of small-scale agriculture using large-scale agricultural machinery for large-scale, intensive and modern production, realized the successful docking of small-scale family management system and modern agricultural production mode, and provided a useful reference for taking the road of agricultural modernization with Chinese characteristics [1]. After more than 30 years of development, with the development of land transfer, household contract management and social services, the number of agricultural machinery has increased year by year, and the level of agricultural mechanization has steadily improved. Agricultural machinery cross region operation not only brings considerable economic benefits to the manipulator, but also promotes the development of agricultural mechanization, and provides equipment support for high-yield and harvest of grain in Figure 1.
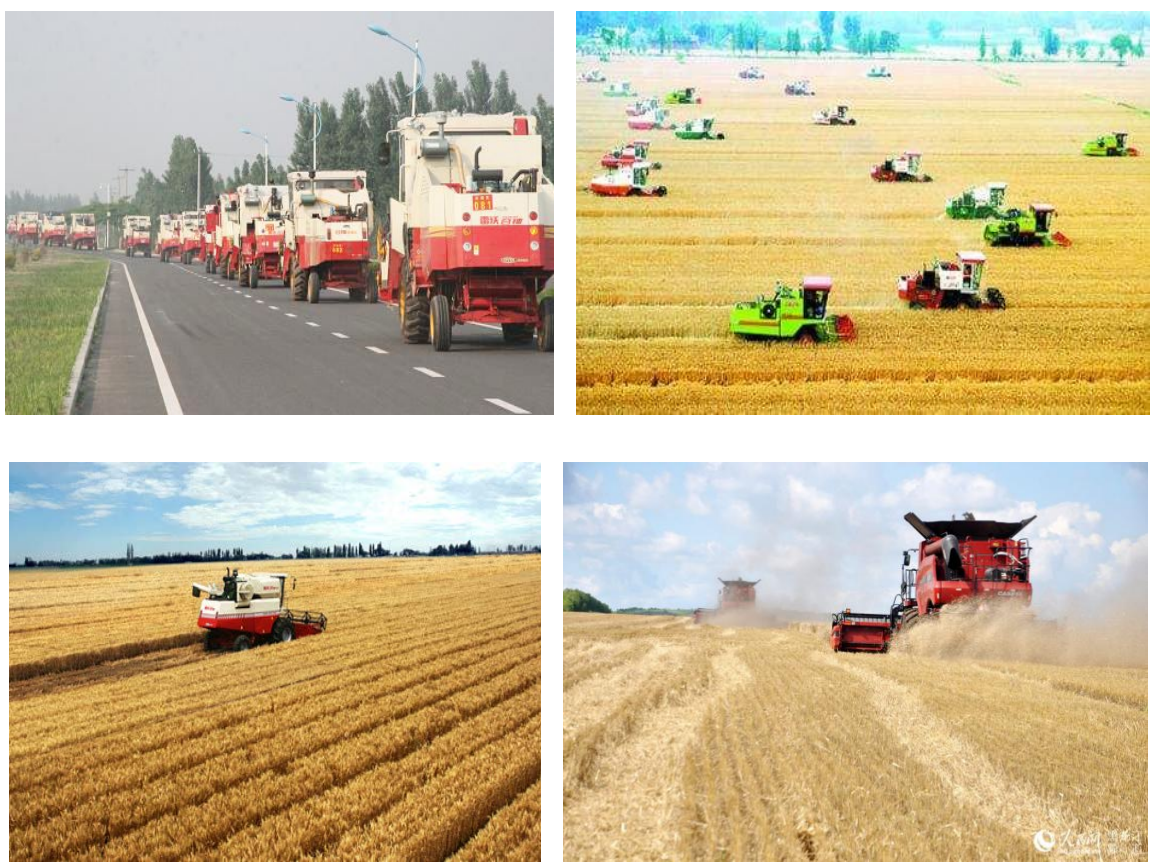

Figure 1. Cross-area work chart of combine harvester in Heilongjiang reclamation area (http://image.baidu.com/search/index?tn=baiduimage\&ct=201326592). 


\section{The Conditions of Agricultural Machinery Trans-Regional Allocation}

\subsection{Regional Differences}

Due to the large latitude, there are some differences in harvest time of wheat, rice and other crops in China. Even in the same province, the differences in harvest time caused by differences in ecological conditions can reach a week or even more than a month, making it possible to allocate agricultural machinery.

\subsection{Economic Efficiency}

Compared with the operation in the same area, the cross region operation can extend the operation time by 3 - 4 times, greatly improve the use efficiency of agricultural machinery, greatly shorten the investment payback period of purchasing machinery, and greatly improve the enthusiasm of agricultural machinery operators to provide services.

\subsection{Improve Labor Productivity}

Compared with manual harvesting, machinery can replace a large number of labor force and greatly improve labor productivity, which is welcomed by farmers.

\section{Analysis on the Current Situation of Agricultural Machinery Trans-Regional Allocation Mode}

\subsection{The Allocation of Agricultural Machinery Is Decided by the Owner of Agricultural Machinery}

In the current practical production operation, the operation information of agricultural machinery mainly depends on the experience of the owner to determine the operation area and place subjectively. There are many factors affecting the decision-making of the owner, including time, place, road condition, model and quantity, operation capacity, operation price, operation area, idle time, social benefits, etc. Due to the lack of scientific basis, the subjective decision-making scheme of agricultural machinery allocation lacks of scientific nature, which makes the service cost of agricultural machinery increase and the income is difficult to be maximized. Among the many influencing factors, how to choose the operation location and operation path to get the most benefit is not only a problem that the owner cannot draw a conclusion intuitively, but also a very difficult decision-making problem [2].

\subsection{The Allocation of Agricultural Machinery Shall Be Organized by Relevant Government Departments}

In the busy season, when the extreme weather is about to happen, the relevant government departments will organize to complete the task of harvesting and planting in a specific time. Most of the government departments are also based 
on subjective experience [3]. How to allocate agricultural machinery scientifically in order to complete the task better is a difficult but necessary problem for the management department.

\subsection{The Allocation of Agricultural Machinery Shall Be in the Charge of Agricultural Machinery Cooperators}

With the development of cooperative economy, there are more and more agricultural machinery cooperators. They mainly rely on subjective experience to allocate agricultural machinery through manual distribution, voice communication and other traditional methods. The agricultural machinery cooperator contacts the agricultural machinery owner through mobile phone to know the status of agricultural machinery and the completion of farmland tasks in real time. At the same time, contact with the grower to understand the information of the order to be operated, and according to the actual situation and experience, select and dispatch the idle agricultural machinery closest to the operation point to transfer to another operation point for harvesting service [4]. However, this traditional scheduling method is prone to the problems of job information lag, poor timeliness and low efficiency.

\subsection{The Allocation of Agricultural Machinery Is Controlled by Wireless Communication Technology}

With the progress of science and technology, the continuous progress of navigation system, satellite positioning and other technologies, in order to adapt to the development of new technologies, some agricultural machinery owners use wireless communication technology to establish agricultural machinery monitoring system to achieve real-time monitoring of harvester operation position and status in cross regional operation, but in terms of scheduling decision-making, it still depends on the subjective allocation and decision-making of dispatchers, without the farmland task and scientific and systematic planning of harvester resources and various influencing factors [5].

\section{Common Problems in the Process of Cross Regional Allocation of Agricultural Machinery}

\subsection{Waste of Resources Due to Unreasonable Planning}

In the region, due to the unreasonable sequence of plot operation, if agricultural machinery in the process of changing farmland plot has many detours, it will reduce the working efficiency, cause waste of time, oil, human resources and other resources, and increase the operating cost. Outside the region and in the process of cross regional deployment, there is a lack of overall scientific system planning, unclear understanding of the transfer path, road, weather and operation site, blind based on the needs of the owner or subjective judgment, which is easy to lead to the coordination between the supply and demand of machines and tools and waste of resources. On the one hand, idle agricultural machinery 
cannot arrive at the operation site on time, delaying agricultural time. On the other hand, working agricultural machinery rushed to reduce work efficiency [6].

\subsection{Unreasonable Land Area and Power Allocation of Agricultural Machinery}

In the allocation of agricultural machinery, is the greater the horsepower of agricultural machinery, the best benefit? The allocation of agricultural machinery should be based on the main terrain characteristics, soil type, plot area, ridge length, etc. of the operation site, and the appropriate model and quantity of harvester should be allocated. The suitability of harvester and plot will have a great impact. It is not necessarily the best benefit to select high-power harvester for small plot.

\subsection{Small Scale Experience of Agricultural Resources Restricts the Allocation of Agricultural Machinery}

To a certain extent, the difficulty in the allocation of agricultural machinery stems from small-scale operation. The low efficiency of agricultural production and too small cultivated area directly affect the demand tendency of agricultural machinery market for agricultural machinery scale.

\section{Ways and Measures to Improve the Trans-Regional Allocation Mode of Agricultural Machinery}

\subsection{Ensure Efficient Operation of Agricultural Machinery}

Agricultural machinery is often accompanied by overload operation and lack of inspection and maintenance during the busy period. The long-term non intermittent operation of agricultural machinery is the main cause of a variety of agricultural machinery failures. Due to the lack of rest and maintenance, the long-term work of agricultural machinery in a bad state cannot only improve the efficiency of labor production, but also seriously affect the production progress due to a variety of failure problems [7]. Therefore, in order to improve the efficiency of agricultural machinery, it is necessary to adopt intermittent operation or rotation operation to ensure the standardized use of agricultural machinery.

\subsection{Strengthen the Utilization Rate of Advanced Agricultural Machinery and Equipment}

Encourage advanced agricultural machinery to carry out service operations in the region. Farmers complete high-quality agricultural production requirements by leasing advanced agricultural machinery, which not only avoids idle problems caused by excessive purchase of agricultural machinery, but also completes corresponding agricultural production tasks. The owners of advanced agricultural machinery and equipment can also obtain good economic income through service operations. 


\subsection{Encourage the Cross Regional Operation of Advanced Agricultural Machinery}

Encouraging the cross regional operation of advanced agricultural machinery and the compliance of agricultural production with the seasons leads to the idle of agricultural machinery resources. Through the cooperation between regions, the operation time of agricultural machinery can be extended in a large range to ensure the efficient utilization of advanced agricultural machinery and equipment [8].

\subsection{Strengthen the Management Means of Agricultural Machinery}

The agricultural machinery management department should effectively ensure the utilization rate of agricultural machinery resources through scientific management. Abandon the extensive management mode in the past, carry out refined management on agricultural machinery and equipment, do a good job in the registration and statistics of advanced agricultural machinery and equipment, and clarify the operation characteristics and application scope of agricultural machinery and equipment. In order to ensure the steady progress of the utilization of agricultural machinery resources, we should formulate a scientific and advanced allocation system of agricultural machinery resources and a reasonable management and allocation plan based on the characteristics of agricultural machinery. Do a good job in communication and coordination between agricultural machinery to be deployed and the objects to be served to ensure the reliable implementation of agricultural machinery resource allocation and service operations.

\subsection{Increase the Quantity of Advanced Agricultural Machinery and Equipment}

According to the actual situation of agricultural mechanization production, the quantity of advanced agricultural machinery is still insufficient. The technical backwardness of small agricultural machinery will seriously affect the efficiency of agricultural production, and is not conducive to the popularization of large-scale advanced agricultural machinery. Agricultural Machinery Extension departments should pay attention to the promotion of advanced agricultural machinery and equipment, and promote the improvement of the retention of advanced agricultural machinery [9].

\subsection{Promote Land Circulation and Create Conditions for Cross Regional Allocation of Agricultural Machinery}

Through the optimization of agricultural production and management mode to reduce the use of small and backward agricultural machinery, while reducing the number of agricultural machinery, optimize the quality and scientific and technological content of agricultural machinery. At the same time, we will promote the transfer of land, create convenient conditions for the work of high-quality agricultural machinery, and achieve the goal of agricultural production through 
a small number of high-quality agricultural machinery.

At present, the process of Agricultural Mechanization in China reflects the characteristics different from that in developed countries, which is the imbalance of the level of agricultural mechanization. Due to the differences of geographical and climatic conditions in China, the process of agricultural mechanization will reflect the development characteristics of different regions, different production conditions and different economic development levels. In order to guide the efficient harvesting of agricultural crops, standardize the management of agricultural machinery, so as to accelerate the further development of China's agriculture and realize the rapid development of agricultural economy, this paper studies the establishment and practical application of the principle of cross region intelligent scheduling of agricultural machinery.

\section{Funding}

Social Science Fund Project of Heilongjiang Province (CN) (NO. 16JYB16).

Post-doctoral Fund Project of Government of Heilongjiang Province (CN) (NO. LBH-Z15026).

Ph.D Startup Fund Project of Heilongjiang Bayi Agricultural University (CN) (NO. XDB2015-06).

Social Science Fund Project of Heilongjiang Province (CN) (NO. 19JYB023).

\section{Conflicts of Interest}

The authors declare no conflicts of interest regarding the publication of this paper.

\section{References}

[1] Cao, G.Q., Zhang, Z.Y. and Yi, Z.C. (2007) Report of Agricultural Machinery Trans-Regional Operations in Hebei, Shandong, Henan, Jiangsu, and Anhui. Journal of Agricultural Mechanization Research, No. 6, 7-10+14.

[2] Chen, Y.Y. (2014) Thinking about the Problems Faced by the Trans Regional Operation of Agricultural Machinery. Fujian Agriculture, No. 8, 124.

[3] Camarena, E.A., Gracia, C. and Cabrera Sixto, J.M. (2004) A Mixed Integer Linear Programming Machinery Selection Model for Multifarm Systems. Biosystems Engineering, 87, 145-154. https://doi.org/10.1016/j.biosystemseng.2003.10.003

[4] Hu, C. and Wu, H.R. (2013) Multi-Object Comprehensive Decision Test for Deploying. Journal of Agricultural Mechanization Research, No. 3, 46-49.

[5] Liu, L., Liu, Y. and Wang, X.L. (2019) Research on Agricultural Machinery Allocation Based on Genetic Algorithm. Journal of Agricultural Mechanization Research.

[6] Li, X.L., Li, Z.G. and Chen, H. (2013) Beijing Agricultural Machinery Operation Scheduling Management and Precision Operation System. Agricultural Engineering, No. S2, 44-48+50.

[7] Li, Z.G. and Chen, H. (2013) Beijing Agricultural Machinery Operation Scheduling Management and Precision Operation System. Agricultural Engineering, No. S2, $44-48+50$.

[8] Si, H. (2004) The Development Status, Benefit Analysis and Countermeasure Re- 
search of China's Trans Regional Machine Harvest. Agricultural Engineering, No. 1, 1-8.

[9] Zhang, J.W. (2019) Efficient Utilization and Rational Allocation of Agricultural Machinery Resources. Agricultural Magination Using \& Maintenance, No. 7. 